\title{
Nitrate accumulation in leafy vegetables and its relationship with water
}

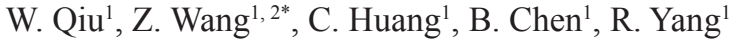 \\ ${ }^{1}$ Key Laboratory of Plant Nutrition and Agro-environment in Northwest China, Ministry of Agriculture, College of Natural \\ Resources and Environment, Northwest A \& F University, Yangling Shaanxi 712100, China. ${ }^{2}$ State Key Laboratory of Crop Stress \\ Biology in Arid Areas , Northwest A \& F University, Yangling Shaanxi 712100, China. *Corresponding author: zhwang@263.net
}

\begin{abstract}
Present studies show that nitrate accumulation is the major factor influencing the water uptake by vegetables, but there is lack of knowledge on how the relationship between nitrate and water concentrations in different vegetable tissues. We determined nitrate accumulation and water content in vegetables of rape, Chinese cabbage, and spinach under different nitrogen levels (experiment I), 29 spinach cultivars (experiment II), and 27 rape cultivars (experiment III). The results from experiments I-III showed a highly linear relationship between nitrate accumulation and water content, and the levels thereof in different organs of the vegetables revealed that the petiole exhibited the best correlation between them compared with the root and leaf blade. These suggest that (1) vegetables with high water content have high nitrate content, (2) water content in the petiole can be used to screen cultivars with low levels of nitrate accumulation, and (3) increasing soil water content in agronomic practice is essential to decreasing nitrate accumulation in vegetables.
\end{abstract}

Keywords: plant water, petiole, leaf blade, root, nitrogen rate

\section{Introduction}

Vegetables are an important component of the human diet and considered to be a high source of nitrate accumulation (Zhong et al., 2002), accounting for $72 \%-94 \%$ of the total nitrate intake of humans (Walker 1990). Nitrate by itself is relatively nontoxic; however, it may be endogenously transformed to nitrite, which can react with amines and amides to produce $N$-nitroso compounds (Santamaria 2006; Yordanov et al., 2001). These compounds have been related to an increased risk of diseases (Choi et al., 2007; Santamaria 2006). Excessive nitrate can also block iodide uptake of the sodium iodide symporter in a competitive manner (Tonacchera et al., 2004). For this reason, nitrate in vegetables has received increasing attention. In recent decades, much research has been conducted to minimize the accumulation of nitrate in vegetables. However, nitrate accumulation is a complex trait; plant nitrate content is affected by many internal and external factors (Marquez-Quiroz et al., 2014; Tamme et al., 2006; Wang and Li 1996). Moreover, nitrate concentration varies markedly with plant species/cultivars (Gil et al., 2012; Tamme et al., 
2006; Thomson et al., 2007; Umar et al., 2007). Thus, selection of genotypes that accumulate fewer nitrates may contribute significantly to a reduction in nitrate consumption by humans through vegetables.

Previous studies showed that nitrate accumulation in vegetables is related to the water content in vegetable tissues (Burns et al., 2012; Reinink et al., 1987). Absorption of excessive nitrate levels by plants causes their water potential to decline. To maintain the water potential balance, plants should absorb more water at the same time. Cárdenas-Navarro et al., (1999) suggested that nitrate accumulation is the major factor influencing the water uptake by vegetables. Reinink et al., (1987) showed that genotypes with low water content could have high carbohydrate content in their vacuoles and thus need small amounts of nitrate to maintain their osmotic value. These findings led to research interest on whether a causal or inherent relationship exists between water content and nitrate accumulation in vegetables. However, absolute evidence to confirm this relationship remains elusive, because most studies were carried out only once or with one type of vegetable. Therefore, this study aimed to evaluate the relationship between nitrate accumulation and water content in vegetable tissues under different levels of nitrogen application rates and with different leafy vegetable varieties and different cultivars of the same vegetable.

\section{Materials and Methods}

\subsection{Experiment $I$}

A pot experiment was conducted in No. 1 Crop Experimental Station of Northwest A \& F University (hereinafter referred to as "A \& F"), Yangling, Shaanxi Province, China. Three leafy vegetables, namely, rape (Brassica chinensis var. oleifera), Chinese cabbage (Brassica rapa var. chinensis), and spinach (Spinacia oleracea L.), were sown in plastic pots measuring $25 \mathrm{~cm} \times 30 \mathrm{~cm}$ (diameter $\times$ depth) and filled with 5 $\mathrm{kg}$ of field soil, which was loessial soil taken from a fallow field in A\&F and passed through a 4-mm sieve for use. The levels of soil organic matter, total nitrogen $(\mathrm{N})$, nitrate $\mathrm{N}\left(\mathrm{NO}_{3}^{-}-\mathrm{N}\right)$, ammonium $\mathrm{N}\left(\mathrm{NH}_{4}^{+}-\mathrm{N}\right)$, Olsen phosphorus $(\mathrm{P})$, available potassium $(\mathrm{K})$, and $\mathrm{pH}$ were $11.19 \mathrm{~g} \mathrm{~kg}^{-1}, 0.91 \mathrm{~g} \mathrm{~kg}^{-1}, 37.45 \mathrm{mg} \mathrm{kg}^{-1}, 13.15 \mathrm{mg} \mathrm{kg}{ }^{-1}$, $23.93 \mathrm{mg} \mathrm{kg}^{-1}, 97.65 \mathrm{mg} \mathrm{kg}^{-1}$, and 7.78 , respectively. Five nitrogen treatments $(0.0,0.2,0.4,0.6$, and $0.8 \mathrm{~g}$ $\mathrm{N} \mathrm{kg}^{-1}$ soil) were applied, and each had four replicate pots. Rape, Chinese cabbage, and spinach were planted on 4 September 2001, and six plants were grown in each pot. The pots were housed in a glasshouse, weeded, and scarified weekly. Soil water content was controlled at $20 \%$ by weight method. Nitrogen fertilizer application in the form of $\mathrm{KNO}_{3}$ was split into two parts: half was applied before sowing, and the other half was added 4 weeks later. In addition, $0.2 \mathrm{~g} \mathrm{P}_{2} \mathrm{O}_{5} \mathrm{~kg}^{-1}$ soil was applied as the basal fertilizer.

Fully expanded leaves from the same position were sampled 9 weeks after planting, flushed, and washed with flowing water to obtain the whole plants. They were then divided into roots, petioles, leaves, and stems to determine the nitrate concentration in different organs.

\subsection{Experiment II}

A pot experiment using 29 spinach cultivars was also conducted in the greenhouse in A\&F from October 2000 to March 2001. The soil was loessial soil collected from the top $20 \mathrm{~cm}$ layer from a field in A\&F. The levels of soil organic matter, total $\mathrm{N}, \mathrm{NO}_{3}^{-}-\mathrm{N}, \mathrm{NH}_{4}^{+}-\mathrm{N}$, Olsen $\mathrm{P}$, available $\mathrm{K}$, and $\mathrm{pH}$ were $12.8 \mathrm{~g} \mathrm{~kg}^{-1}, 1.0 \mathrm{~g} \mathrm{~kg}^{-1}, 41.5 \mathrm{mg}$ $\mathrm{kg}^{-1}, 11.2 \mathrm{mg} \mathrm{kg}^{-1}, 25.9 \mathrm{mg} \mathrm{kg}^{-1}, 91.4 \mathrm{mg} \mathrm{kg}^{-1}$, and 7.69, respectively.

Spinach cultivars were grown in a dark brown plastic pot filled with $4.0 \mathrm{~kg}$ of air-dried field soil and with soil moisture content of $20 \% \pm 2 \%$. Each spinach cultivar had four replicate pots, and each pot contained $0.30 \mathrm{~g} \mathrm{~N} \mathrm{~kg}^{-1}$ soil (low $\mathrm{N}$ rate) or $0.60 \mathrm{~g} \mathrm{~N} \mathrm{~kg}^{-1}$ soil (high $\mathrm{N}$ rate) with urea, $0.13 \mathrm{~g} \mathrm{P}_{2} \mathrm{O}_{5} \mathrm{~kg}^{-1}$ soil with calcium superphosphate, and six plants of spinach cultivars.

Spinach samples were taken twice - between 8:30 and 9:30 AM on 12 March and 25 March 2001. The samples 
were placed in a marked plastic bag, which was then sealed and stored in a refrigerated box. The shoots were differentiated into various organs (leaf blade, petiole, and stem). Each organ was weighed to obtain fresh weight and then cut into small pieces, mixed, divided into two parts, and sealed in marked plastic bags. One part was used to determine the nitrate concentration and kept in the refrigerator at $0-4{ }^{\circ} \mathrm{C}$, whereas the other part was used to determine the amount of water and dry weight.

\subsection{Experiment III}

A field experiment was conducted in A \& F from August to October 2009. The soil used was loessial soil, and the soil $\mathrm{pH}$, total $\mathrm{N}$, total $\mathrm{C}$, available $\mathrm{P}$ (Olsen $\mathrm{P}$ ), and available $\mathrm{K}$ measured $8.57,1.14 \mathrm{~g} \mathrm{~kg}^{-1}, 12.8 \mathrm{~g} \mathrm{~kg}^{-1}, 31.0$ $\mathrm{mg} \mathrm{kg}^{-1}$, and $137 \mathrm{mg} \mathrm{kg}^{-1}$, respectively. Twenty-seven rape cultivars supplied by the oilseed rape breeding laboratory of the College of Agronomy of A\&F were used in this experiment. Two treatments with nitrogen at fertilizer rates of $60 \mathrm{~kg} \mathrm{~N}^{-1}$ (low $\mathrm{N}$ rate) and $240 \mathrm{~kg} \mathrm{~N} \mathrm{ha}^{-1}$ (high $\mathrm{N}$ rate) were applied, with each treatment having three replicate plots and the area of each plot being $88 \mathrm{~m}^{2}$. All plots were allocated to the field randomly. N, P (120 kg $\left.\mathrm{P}_{2} \mathrm{O}_{5} \mathrm{ha}^{-1}\right)$, and $\mathrm{K}(120 \mathrm{~kg}$ $\mathrm{K}_{2} \mathrm{O}$ ha $^{-1}$ ) fertilizers (urea, $\mathrm{N}: 46 \%$; superphosphate, $\mathrm{P}_{2} \mathrm{O}_{5}: 12 \%$; potassium sulfate, $\mathrm{K}_{2} \mathrm{O}: 50 \%$ ) were applied to all plots prior to sowing. Plant samples were taken as described in Section Experiment II.

\subsection{Determination of nitrate concentration in plants}

Nitrate concentration was measured according to the method described by Wang and Li (1996). Nitrate was extracted with distilled water. Two grams of fresh sample and $0.50 \mathrm{~g}$ of arenaceous quartz were ground with a pestle and mortar and then completely transmitted to a centrifuge tube with a definite quantity of distilled water. After centrifugation, the supernatant was used for nitrate concentration assay with flow injection analysis after Cd-catalyzed reduction to $\mathrm{NO}_{2}$-(FIASTAR 5000). The nitrate concentration in shoots was calculated from the concentrations in the leaf blade, petiole, and stem.

\subsection{Statistical analysis}

Statistical analysis was performed using SAS 8.0 (SAS Institute Inc., USA), and the graphs were illustrated by SigmaPlot 12.5 (Systat Software Inc., USA).

\section{Results}

\subsection{Nitrate-water relationship at the whole plant level}

3.1.1. Nitrate and water in whole plants under different nitrogen rates

In experiment $\mathrm{I}$, the water and nitrate contents in whole plants of rape, Chinese cabbage, and spinach were measured under different nitrogen supply rates. They were found to change in a similar way among the three leafy vegetables (Figure 1): at a lower nitrogen rate $\left(0-0.4 \mathrm{~g} \mathrm{~N} \mathrm{~kg}^{-1}\right.$ soil for rape; $0-0.2 \mathrm{~g} \mathrm{~N} \mathrm{~kg}^{-1}$ soil for Chinese cabbage and spinach), the contents increased when the nitrogen supply rate increased but decreased when the rate continuously increased. Correlation analysis showed that the nitrate and water concentrations were positively correlated $(p<0.05)$ in rape, Chinese cabbage, and spinach. This indicated that nitrate accumulation in the three leafy vegetables increased dramatically as water content increased.

3.1.2. Nitrate and water contents in whole plants of 29 spinach cultivars

In experiment II, the water and nitrate contents in whole plants of 29 spinach cultivars were detected under low and high nitrogen rates (Figure 2). The nitrate and water contents were higher at low nitrogen rate (from 6.7 to $15.0 \mathrm{~g} \mathrm{~N} \mathrm{~kg}^{-1}$ dry weight (DW) for nitrate and from 5.6 to $10.9 \mathrm{~g} \mathrm{~g}^{-1} \mathrm{DW}$ for water) than those at high nitrogen rate (from 1.8 to $7.2 \mathrm{~g} \mathrm{~N} / \mathrm{kg} \mathrm{DW}$ for nitrate and from 6.2 to $8.8 \mathrm{~g} \mathrm{~g}^{-1} \mathrm{DW}$ for water). However, the nitrate and water contents were still found to be positively linearly correlated $(p<0.01)$ over the 29 spinach cultivars at both low and high nitrogen application rates. 


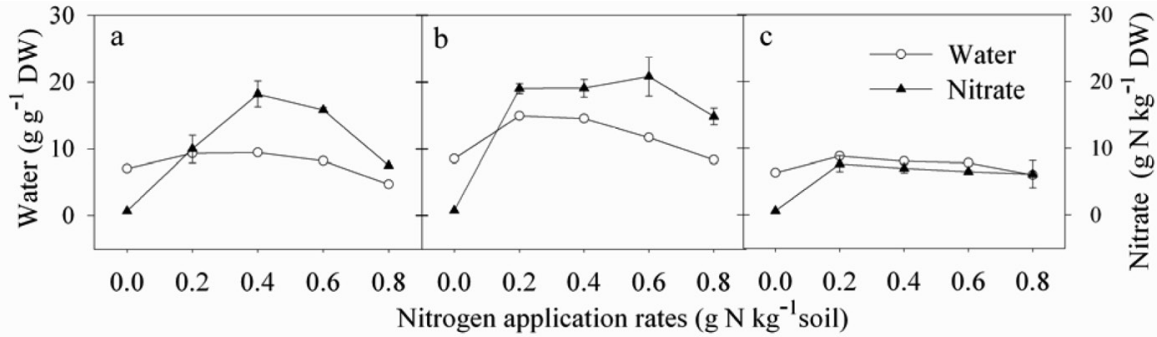

Figure 1. Nitrate and water contents in whole plants under different nitrogen rates in experiment I: (a) rape; (b) Chinese cabbage; (c) spinach

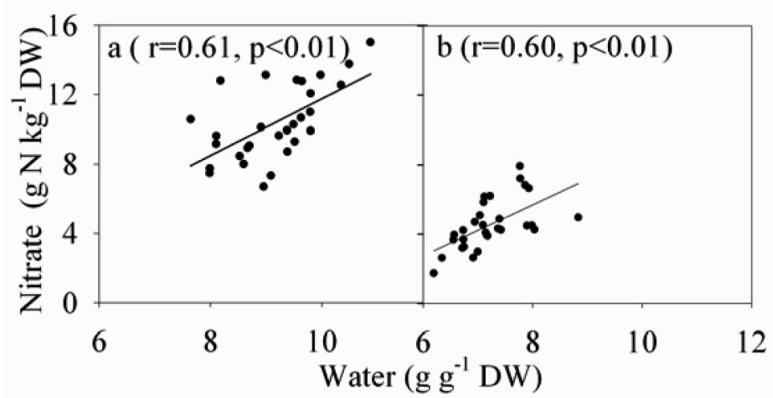

Figure 2. Relationship between nitrate and water contents in whole plants of 29 spinach cultivars in experiment II: (a) low $\mathrm{N}$ rate $\left(0.30 \mathrm{~g} \mathrm{~kg}^{-1}\right.$ soil $)$; (b) high $\mathrm{N}$ rate $\left(0.60 \mathrm{~g} \mathrm{~kg}^{-1}\right.$ soil $)$

\subsection{Nitrate and water contents in different organs of vegetables}

In experiments I-III, the nitrate and water contents in different organs (leaf blade, stem, and petiole) of the three leafy vegetables were also detected. In experiment $\mathrm{I}$, the nitrate content in the petiole (from 0.5 to $64.4 \mathrm{~g} \mathrm{~N} \mathrm{~kg}^{-1} \mathrm{DW}$ ) of the three leafy vegetables was markedly higher than that in the leaf blade (from 0.1 to $10.6 \mathrm{~g} \mathrm{~N} \mathrm{~kg}^{-1} \mathrm{DW}$ ), whereas the nitrate content in the root (from 0.2 to $6.3 \mathrm{~g} \mathrm{~N} \mathrm{~kg}^{-1}$ DW) was the lowest among the organs (Figure 3). For water content, a similar trend was observed as follows: 5.5 to $25.1 \mathrm{~g} \mathrm{~g}^{-1} \mathrm{DW}$ in the petiole, 3.5 to $14.1 \mathrm{~g} \mathrm{~g}^{-1} \mathrm{DW}$ in the root, and 6.1 to $12.2 \mathrm{~g} \mathrm{~g}^{-1} \mathrm{DW}$ in the blade. In addition, the nitrate and water contents were significantly and positively correlated $(p<0.01)$ in the petiole of all three leafy vegetables (rape, Chinese cabbage and spinach); however, no such linear relationship was found in other organs except in the root of rape.

Similar to experiment I, the nitrate and water contents were still higher in the petiole than in the other organs of the 29 spinach cultivars under low and high nitrogen rates in experiment II (Figure 4). In addition, the positively linear correlation between nitrate and water contents in the petiole was significant $(p<0.01)$ over the 29 spinach cultivars under both nitrogen rates (Figure 4). However, the relationship in the leaf blade or root was only observed on occasion. 


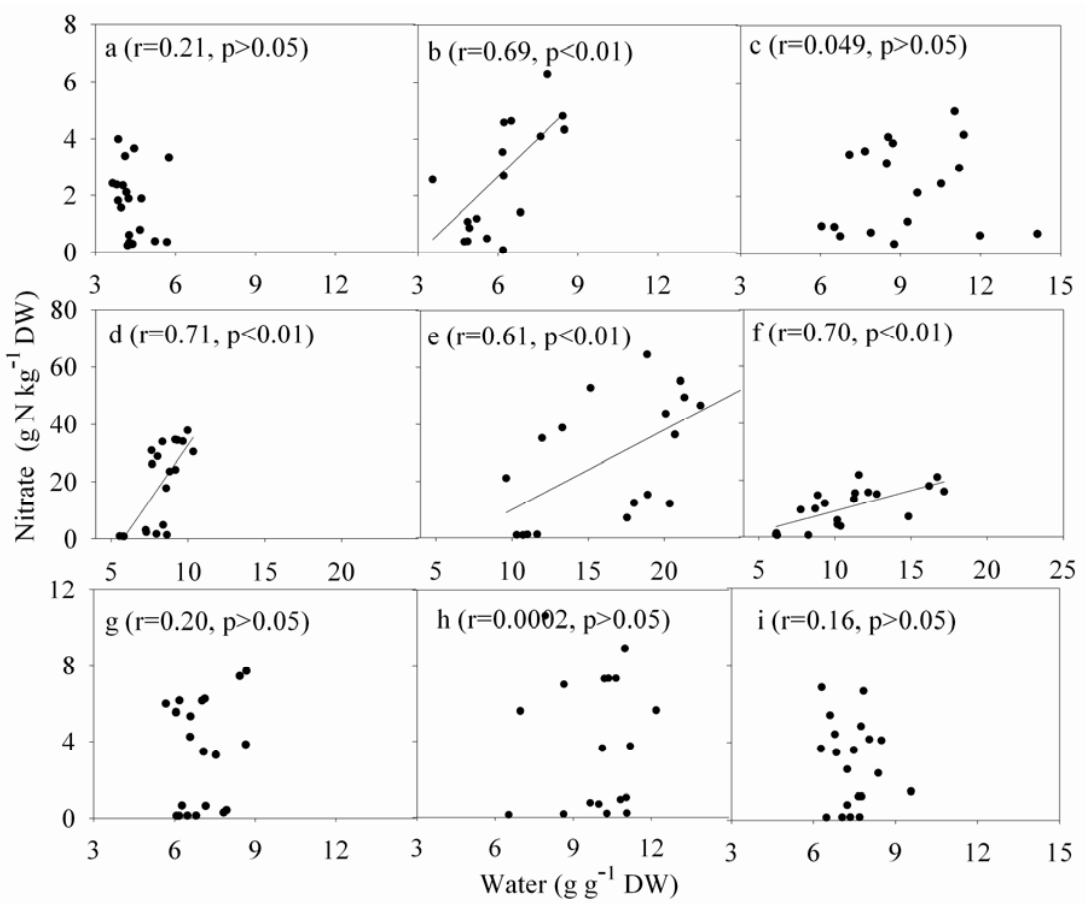

Figure 3. Relationship between nitrate and water contents in different organs of rape (a, d, g), Chinese cabbage (b, $\mathrm{e}, \mathrm{h})$, and spinach $(\mathrm{c}, \mathrm{f}, \mathrm{i})$ in experiment I: $(\mathrm{a}-\mathrm{c})$ root; $(\mathrm{d}-\mathrm{f})$ petiole; $(\mathrm{g}-\mathrm{i})$ leaf blade
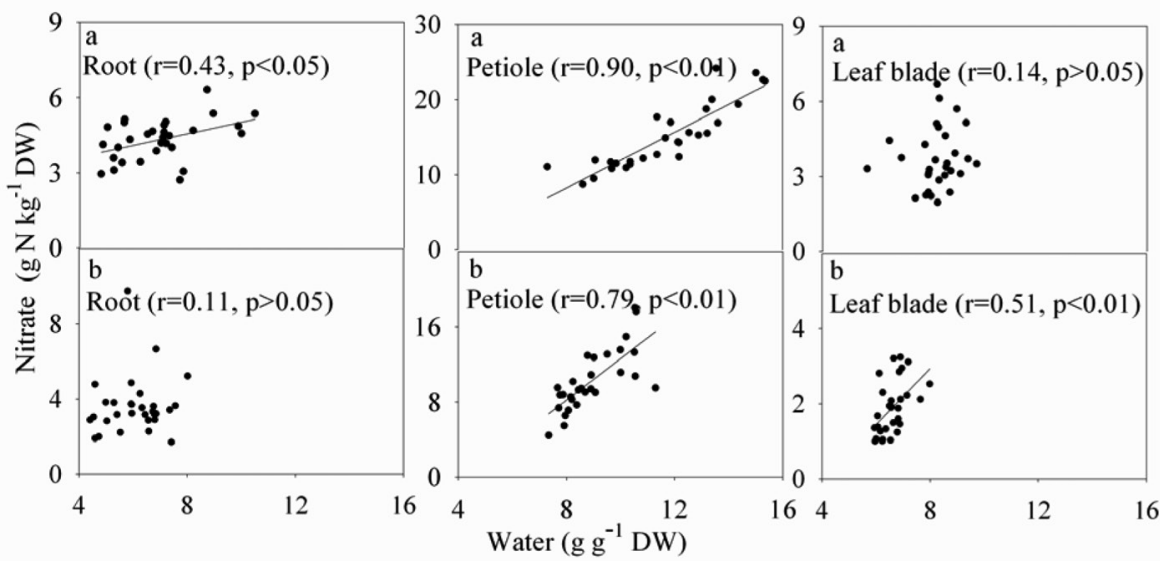

Figure 4. Relationship between nitrate and water contents in different organs of 29 spinach cultivars in experiment II: (a) low $\mathrm{N}$ rate $\left(0.30 \mathrm{~g} \mathrm{~kg}^{-1}\right.$ soil); (b) high $\mathrm{N}$ rate $\left(0.60 \mathrm{~g} \mathrm{~kg}^{-1}\right.$ soil $)$ 


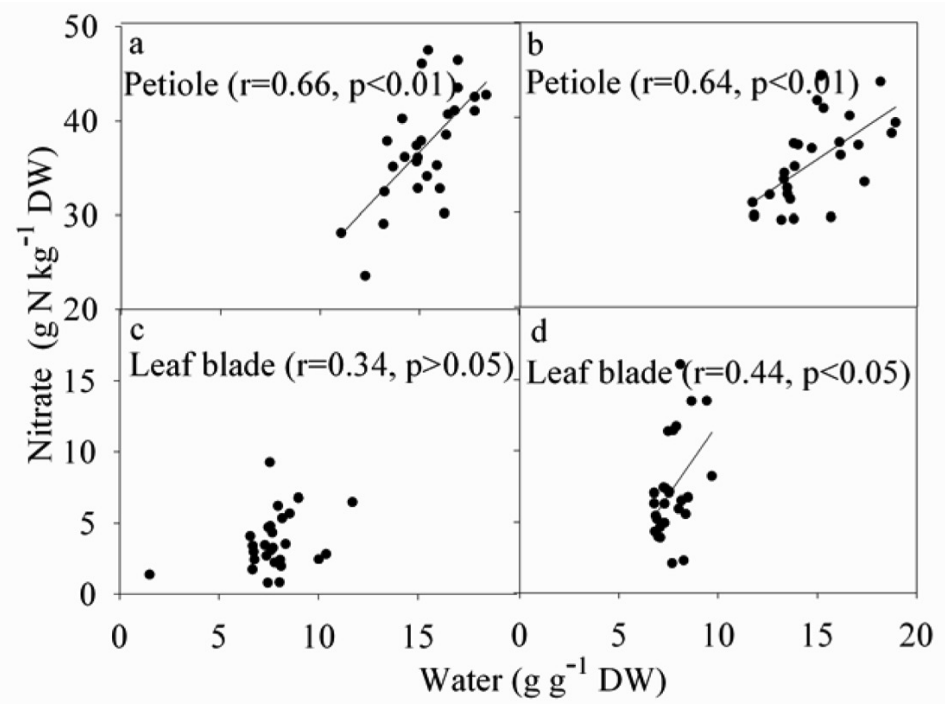

Figure 5. Relationship between nitrate and water contents in different organs of 27 rape cultivars in experiment III: (a, c) low $\mathrm{N}$ rate $\left(60 \mathrm{~kg} \mathrm{~N} \mathrm{ha}^{-1}\right)$; (b, d) high $\mathrm{N}$ rate $\left(240 \mathrm{~kg} \mathrm{~N} \mathrm{ha}^{-1}\right)$

In experiment III, the nitrate and water contents were only measured in the petiole and leaf blade of 27 rape cultivars, and a significant linear relationship between them was only found in the petiole of the 27 rape cultivars (Figure 5).

\section{Discussion}

The results from experiments I-III showed a highly linear relationship between the nitrate and water contents of the whole plants. These were positively linearly correlated $(p<0.01)$ over 29 spinach cultivars under both low and high nitrogen rates (Figure 2). Our findings are in agreement with those of Burns et al., (2012) and Cárdenas-Navarro et al., (1999), who indicated that the nitrate concentration and water content in the shoot were positively associated in different vegetable cultivars. Meanwhile, the change pattern of nitrate and water contents was concurrent among rape, Chinese cabbage, and spinach when the nitrogen supply rate increased (Figure 1). Further statistical analysis also showed that the relationship between nitrate and water contents in the whole plant was positively linearly correlated. This implied that the nitrate concentration was related either directly or indirectly to the volume of water in their plant tissues. Burns et al., (2011) demonstrated that the cultivars with higher levels of nitrate accumulation had greater volumes of tissue water, which would have increased the dilution of nitrate and helped adjust for differences in their combined concentration in the shoot, and that the volume of shoot sap was greater in cultivars with higher nitrate levels to help offset the effects of their large nitrate concentration. These results indicate that genotypic variation in nitrate accumulation is associated with differences in water content, which means that, at least for rape, Chinese cabbage, and spinach, water content could be used as a screening indicator for selecting varieties that have low levels of nitrate accumulation. 
Further analysis of the relationship between nitrate and water contents in different organs of vegetables revealed that the petiole exhibited the best correlation of nitrate accumulation to water content compared with the root and leaf blade (Figures. 3-5). A positive linear relationship between nitrate and water contents in the petiole in all three experiments was observed, whereas a positive linear relationship between nitrate and water contents in the root and leaf blade only occurred on occasion (Figures. 3-5). These findings differ from the results reported by Cárdenas-Navarro et al., (1999), who found that a significant linear relationship between nitrate and water contents occurred in the stem, petiole, and leaf blade of their 19-day-old tomato samples, although they also observed the best correlation in the petiole. In addition, the nitrate and water contents in the petiole of the three leafy vegetables were markedly higher than those in the root and leaf blade (Figures. 3-5). Huang et al., (2010) also found that nitrate accumulated in the petiole was significantly higher than that in the leaf blade, as well as that the petiole was obviously the main organ for nitrate accumulation. Ahmadi et al., (2010) reported that different cultivars exhibited a significant difference in petiole length $(p<0.01)$ and that the highest amounts of nitrate accumulation occurred in the petiole, indicating that cultivars with a shorter petiole length could be more important and should be recommended. These results imply that the petiole is the most sensitive organ for nitrate accumulation, suggesting that the water content in the petiole of a vegetable can be used as an additional indicator for screening cultivars with low levels of nitrate accumulation.

\section{Conclusions}

Different vegetables and levels of $\mathrm{N}$ fertilization showed a highly linear relationship between nitrate accumulation and water content, and the levels thereof in different organs of the vegetables revealed that the petiole exhibited the best correlation between them compared with the root and leaf blade. In addition, nitrate accumulation decreased with increasing soil water content. So, the results suggest that (1) vegetables with high water content have high nitrate content, (2) water content in the petiole can be used to screen cultivars with low level of nitrate accumulation.

\section{Acknowledgements}

The authors express their sincere thanks to the National Key Basic Research Special Funds (2009CB118604), the National Natural Science Foundation of China for Projects (30871596, 30971866 and 40671107), the 111 Project of Chinese Education Ministry, the Innovative Research Team Program and Scientific Research Foundation for new doctor of Northwest A \& F University.

\section{References}

Ahmadi, H., Akbarpour, V., Dashti, F., Shojaeian, A. 2010. Effect of different levels of nitrogen fertilizer on yield, nitrate accumulation and several quantitative attributes of five iranian spinach accessions. Am. Eur. J. Agr. Environ. Sci. 8, 468-473.

Burns, I.G., Durnford, J., Lynn, J., McClement, S., Hand P., Pink, D. 2012. The influence of genetic variation and nitrogen source on nitrate accumulation and iso-osmotic regulation by lettuce. Plant Soil. 352, 321-339.

Burns, I.G., Zhang, K.F., Turne,r M.K., Meacham, M., Al-Redhiman, K., Lynn, J., Broadley, M.R., Hand, P., Pink, D. 2011. Screening for genotype and environment effects on nitrate accumulation in 24 species of young lettuce. J. Sci. Food Agr. 91, 553-562.

Cárdenas-Navarro, R., Adamowicz, S., Robin, P. 1999. Nitrate accumulation in plants, a role for water. J. Exp. Bot. 50, 613-624.

Choi, S.Y., Chung, M.J., Lee, S.J., Shin, J.H., Sung, N.J. 2007. N-nitrosamine inhibition by strawberry, garlic, kale, and the effects of nitrite-scavenging and N-nitrosamine formation by functional compounds in strawberry and garlic. Food Control. $18,485-491$. 
Gil, P.M., Bonomelli, C., Schaffer, B., Ferreyra, R., Gentina, C. 2012. Effect of soil water-to-air ratio on biomass and mineral nutrition of avocado trees. J. Soil Sci. Plant Nutr. 12, 609-630.

Huang, C., Wang, Z., Li, S., Malhi, S.S. 2010. Nitrate in leaf petiole and blade of spinach cultivars and its relation to biomass and water in plants. J. Plant Nutr. 33, 1112-1123.

Marquez-Quiroz, C., Lopez-Espinosa, T., SanchezChavez, E., Garcia-Banuelos, M.L., De la CruzLazaro, E., Reyes-Carrillo, J.L. 2014. Effect of vermicompost tea on yield and nitrate reductase enzyme activity in saladette tomato. J. Soil Sci. Plant Nutr. 14, 223-231.

Reinink, K., Groenwold, R., Bootsma, A. 1987. Genotypical differences in nitrate content in Lactuca sativa L. and related species and correlation with dry matter content. Euphytica. 36, $11-18$

Santamaria, P. 2006. Nitrate in vegetables, toxicity, content, intake and EC regulation. J. Sci. Food Agr. 86, 10-17.

Tamme, T., Reinik, M.M., Roasto, M., Juhkam, K., Tenno, T., Kiis, A. 2006. Nitrates and nitrites in vegetables and vegetable-based products and their intakes by the Estonian population. Food Addit. Contam. 23, 355-361.

Thomson, B., Nokes, C., Cressey, P. 2007. Intake and risk assessment of nitrate and nitrite from New Zealand foods and drinking water. Food Addit. Contam. 24, 113-121.
Tonacchera, M., Pinchera, A., Dimida, A., Ferrarini, E., Agretti, P., Vitti, P., Santini, F., Crump, K., Gibbs, J. 2004. Relative potencies and additivity of perchlorate, thiocyanate, nitrate, and iodide on the inhibition of radioactive iodide uptake by the human sodium iodide symporter. Thyroid. 14, 1012-1019.

Umar, S., Iqbal, M., Abrol, Y. 2007. Are nitrate concentrations in leafy vegetables within safe limits?. Curr. Sci. 92, 355-360.

Walker, R. 1990. Nitrates, nitrites and $\mathrm{N}$-nitrosocompounds, a review of the occurrence in food and diet and the toxicological implications. Food Addit. Contam. 7, 717-768.

Wang, Z.H., Li, S.X. 1996. Relationships between nitrate contents and water, total $\mathrm{N}$ as well as total $\mathrm{P}$ in different organs of vegetable plants. Plant Nutr. Fert. Sci. 2, 144-152 (in Chinese with English abstract).

Yordanov, N., Novakova, E., Lubenova, S. 2001. Consecutive estimation of nitrate and nitrite ions in vegetables and fruits by electron paramagnetic resonance spectrometry. Anal. Chim. Acta. 437, 131-138.

Zhong, W., Hu, C., Wang, M. 2002. Nitrate and nitrite in vegetables from north China, content and intake. Food Addit. Contam. 19, 1125-1129. 